\title{
Description of physiotherapy services in a mental health institution in Nigeria
}

\begin{abstract}
Physiotherapy has long been recognised as adjunct to drug therapy in the management of individuals with mental illness. However, little evidence existed on the utilization of physiotherapy in mental health especially in developing worlds.

This study reviewed the utilization of physiotherapy in a Mental Health Institution in Lagos, Nigeria and determined its contribution to quality of patient-care in the hospital.

This study involved review of clients' activity profile and patients' record in a federal neuro-psychiatric hospital in Lagos, Nigeria between 2002 and 2006. The hospital records were used as source of information for sociodemographic details. Information on the physical diagnosis was extracted from the patients' records in the departmental records. Data were summarized using descriptive statistics.

Six thousand, four hundred and seventy-three (3.3\%) out of the 195,686

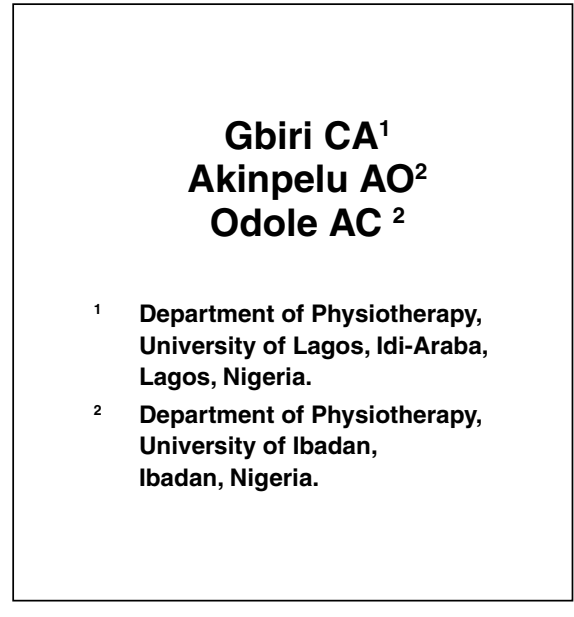
patients of the hospital within the study period enjoyed physiotherapy services.

Only 766 (14\%) of the hospital in-patients enjoyed physiotherapy services. In addition, 808 clients enjoyed the health promotion services. Low back pain $(85 ; 21.7 \%)$, osteo-arthritis $(82 ; 20.9 \%)$, stroke $(64 ; 16.3 \%)$ and shoulder pain (29; 7.4\%) were the most common co-existing health problems referred for physiotherapy.

The importance of physiotherapy in mental health is evidenced in the number of patients/clients who benefited from its services. Therefore, physiotherapy is an integral and indispensible member of the mental health team. However, physiotherapy is still under-utilized in the hospital. This points to the need for proper integration of physiotherapy into mental health team in the hospital and other similar health institutions.
\end{abstract}

KEY WORDS: PHYSIOTHERAPY SERVICE, MENTAL HEALTH TEAM, MENTAL ILLNESS, MENTAL HEALTH INSTITUTION, NIGERIA.

\section{INTRODUCTION}

Mentally ill individuals often present with co-existing health conditions ameliorable to physiotherapy (Gbiri, 2007; 2011a). Poor treatment outcomes and high relapse rate have been major clinical problems confronting mental health clinicians and researchers (Longabaugh et al, 1996; Lawal et al, 1999; Nierman and Lyons, 2001; Lawal et al, 2004). However inter-disciplinary and transdisciplinary approach reduces this menace (Gbiri et al, 2011). It has long been recognised that physiotherapy for individuals with inorganic mental illness in form of exercise therapy/training and relaxation instruction is as effective as drug without the side effects (Hare, 1986; Gbiri et al, 2011). Stress management/coping mechanisms and health promotion offered by physiotherapist are important in prevention and management of some mental illnesses
(Hare, 1986; Gbiri, 2007; 2011). However, it is unfortunate that physiotherapy is not usually part of mental health team in most of the mental health institutions in Nigeria and Africa (Gbiri, 2007; 2011). Physiotherapy is not often utilized for individual with mental illnesses in Nigeria hospitals. There are 35 health institutions with mental health facilities in Nigeria. However, only two not have physiotherapist in their mentalhealth team.

The Federal Neuro-Psychiatric Hospital, Lagos was the first to integrate physiotherapy into its mental health team in Nigeria. The services include health promotion, management of comorbid health conditions amenable to physiotherapy, mental illness prevention and prevention of complication of drug therapy. Establishment of physiotherapy within the mental health institution has made the treatment of the patients who were hitherto referred to hospitals with physiotherapy services less cumbersome. This has made communication and team approach to patient care possible. The in-patients participate in physical exercises/training either as a form of treatment or as diversional therapy. Obesity and body weight increase are often one of the common complications of anti-psychotic drugs (Gbiri, 2011). Patients require physiotherapy to reduce the resultant accumulated weight and maintain ideal weight. Physical exercises

\footnotetext{
Corresponding author:

Caleb A. Gbiri

Department of Physiotherapy,

College of Medicine,

University of Lagos, Idi-Araba,

Lagos, Nigeria.

Email: calebgbiri@yahoo.com; cgbiri@unilag.edu.ng
} 
are also used to reduce stress, inactivity and boredom in patients with mental illness, and increase cardio-pulmonary fitness and mental alertness. Exercises are also used to engage the drug abuse patient and also as an anti-craving modality. However, exercise therapy has not been well utilized for patients in this hospital. This may partly due to the fact that decision to participate in exercise therapy is either left on the interest of the patient, who does not know its benefits or in the hands of the nurses' in-charge who may not have had enough knowledge on the effects and benefits of exercise therapy in mental illness.

The clients in the hospital are those that come for health promotion, stress management and prevention of mental illness. They participate in stress management and health promotion sessions to prevent occurrence/resurgence or emergence of mental health disorder. Various exercises, massage and relaxation are designed to meet the individual need. It has long been realised that some of the skills that the physiotherapist has to offer in the areas of exercise therapy and relaxation instruction are as effective as drug without the commonly observed side effects (Hare, 1986; Gbiri, 2007; 2011). Diversional therapy in form of exercises and games are common phenomena in the management of individual with mental illness in the hospital. This has not also been well utilized in this hospital. This may due to the fact that physiotherapists do not often contribute to decision making during admission of new patients. Individualized physical exercises may reduce the effect of loneliness in depressed individual when taken routinely and meticulously (Gbiri, 2007; 2011). This is usually programmed for the period when the activity of the patient is low. It may also be taken concurrently with chemotherapy. These exercises are always of low intensity, low frequency with mild to moderate duration depending on individual's need and capability.

Despite the various assumed benefits of physiotherapy to either prevent or ameliorate health problems in mentally ill individuals, there is dearth of literature on the contribution of physiotherapy to mental health both in Nigeria and other parts of the world. Therefore, this study examined physiotherapy services and determined its contribution to quality of patient-care in the Federal Neuro-Psychiatric Hospital, Yaba, Lagos, Nigeria between January 2002 and December 2006.

\section{METHOD}

The study was approved by the Ethical Committee of Federal Neuro-Psychiatric Hospital, Yaba, Lagos, Nigeria. A list of all patients who were attended to in Federal Neuro-Psychiatric Hospital, Yaba, Lagos, Nigeria between January 2002 and December 2006 was compiled from the central hospital registers and the physiotherapy department patients' register. The hospital file of each patient within the study period was thoroughly reviewed to obtain demographic information (gender and age) and details about the diagnosis. The files of patients who were not properly registered were excluded. The patients were then subdivided on the basis of in-patients and out-patients. Bio-data of the patients' were extracted from the records in the central hospital register. The information of whether they were referred for physiotherapy was also extracted. Then the information on those who were referred for physiotherapy was then compared with the physiotherapy departmental patients' record for those that actually received physiotherapy services. Data was summarised using frequency and percentage.

Table 1: In-Patient and Out-Patient Attendance for Physiotherapy Services between January 2002 and December 2006

\begin{tabular}{|c|c|c|c|c|c|c|c|c|c|c|c|c|}
\hline \multirow[t]{2}{*}{ Year } & \multirow{2}{*}{$\frac{\text { Age }}{\text { (Years) }}$} & \multicolumn{5}{|c|}{ IN-PATIENTS } & \multicolumn{5}{|c|}{ OUT-PATIENTS } & \multirow[b]{2}{*}{$\begin{array}{c}\text { GROUND } \\
\text { TOTAL }\end{array}$} \\
\hline & & Male & $\begin{array}{c}\% \\
\text { Male }\end{array}$ & Female & $\begin{array}{c}\% \\
\text { Female }\end{array}$ & TOTAL & Male & $\begin{array}{c}\% \\
\text { Male }\end{array}$ & Female & $\begin{array}{c}\% \\
\text { Female }\end{array}$ & TOTAL & \\
\hline \multirow[t]{2}{*}{2002} & $\leq 19$ & 2 & 50.0 & 2 & 50.0 & 4 & _ & _ & - & $\ldots$ & & 4 \\
\hline & $\geq 20$ & 36.6 & 45 & 45 & 63.4 & 71 & 723 & 72.2 & 279 & 27.8 & 1002 & 1073 \\
\hline \multirow[t]{2}{*}{2003} & $\leq 19$ & 5 & 71.4 & 2 & 29.6 & 7 & 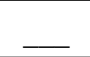 & 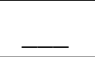 & 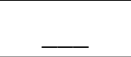 & 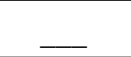 & & 7 \\
\hline & $\geq 20$ & 40 & 58.8 & 28 & 41.2 & 68 & 746 & 67.6 & 351 & 32.4 & 1097 & 1145 \\
\hline \multirow[t]{2}{*}{2004} & $\leq 19$ & 11 & 78.6 & 3 & 21.4 & 14 & - & - & - & - & & 14 \\
\hline & $\geq 20$ & 29 & 48.3 & 31 & 51.7 & 60 & 565 & 56.9 & 428 & 43.1 & 993 & 1558 \\
\hline \multirow[t]{2}{*}{2005} & $\leq 19$ & 7 & 70.0 & 3 & 30.0 & 10 & - & - & 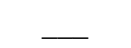 & - & & 10 \\
\hline & $\geq 20$ & 20 & 51.3 & 19 & 48.7 & 39 & 789 & 70.9 & 324 & 29.1 & 1113 & 1902 \\
\hline \multirow[t]{2}{*}{2006} & $\leq 19$ & 7 & 58.3 & 5 & 41.7 & 12 & 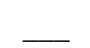 & 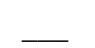 & 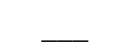 & 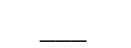 & 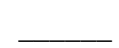 & 7 \\
\hline & $\geq 20$ & 28 & 66.7 & 14 & 33.2 & 42 & 764 & 62.8 & 452 & 37.8 & 1216 & 1980 \\
\hline \multicolumn{2}{|c|}{ TOTAL } & 155 & 50.5 & 152 & 49.5 & 307 & 3587 & 66.2 & 1834 & 33.8 & 4421 & 7928 \\
\hline
\end{tabular}


Table 2: Attendance at the Stress Management and Health Promotion Clinics between January 2002 and December 2006

\begin{tabular}{|c|c|c|c|c|c|c|}
\hline Year & $\begin{array}{l}\text { Age } \\
\text { Group }\end{array}$ & Male & $\%$ Male & Female & $\%$ Female & TOTAL \\
\hline \multirow[t]{2}{*}{2002} & $\leq 19$ & - & - & - & - & - \\
\hline & $\geq 20$ & 95 & 41.5 & 134 & 58.5 & 229 \\
\hline \multirow[t]{2}{*}{2003} & $\leq 19$ & - & - & - & 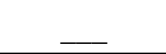 & 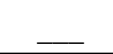 \\
\hline & $\geq 20$ & 89 & 41.8 & 124 & 58.2 & 213 \\
\hline \multirow[t]{2}{*}{2004} & $\leq 19$ & - & - & 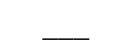 & 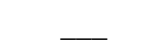 & - \\
\hline & $\geq 20$ & 70 & 43.5 & 91 & 56.5 & 161 \\
\hline \multirow[t]{2}{*}{2005} & $\leq 19$ & _ & - & 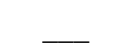 & $\ldots$ & 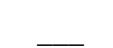 \\
\hline & $\geq 20$ & 52 & 43.0 & 69 & 57.0 & 121 \\
\hline \multirow[t]{2}{*}{2006} & $\leq 19$ & _ & - & - & 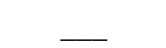 & - \\
\hline & $\geq 20$ & 38 & 45.2 & 46 & 54.8 & 84 \\
\hline \multicolumn{2}{|c|}{ TOTAL } & 344 & 42.6 & 464 & 57.4 & 808 \\
\hline
\end{tabular}

Table 3: Co-Morbid Conditions for which Individuals with Mental Illness are referred for Physiotherapy Services in the Hospital

\begin{tabular}{|c|c|c|c|c|c|c|}
\hline Condition & 2002 & 2003 & 2004 & 2005 & 2006 & TOTAL \\
\hline Low back pain & 15 & 15 & 14 & 9 & 11 & 64 \\
\hline Stroke & 7 & 7 & 13 & 9 & 14 & 50 \\
\hline Neuropathy & - & 1 & - & - & $\ldots$ & 1 \\
\hline Knee(s) Arthritis & 18 & 19 & 13 & 10 & 5 & 65 \\
\hline Hand Injuries & 1 & 1 & 4 & 2 & 3 & 11 \\
\hline Nerve Injuries & - & 4 & _ & _ & - & 4 \\
\hline $\begin{array}{l}\text { Ankle/Foot } \\
\text { Injuries }\end{array}$ & 1 & 2 & - & - & - & 3 \\
\hline $\begin{array}{l}\text { Faecal } \\
\text { Incontinence }\end{array}$ & 1 & 1 & 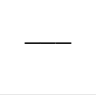 & 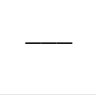 & 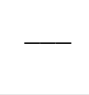 & 2 \\
\hline Monoparesis & 3 & - & - & - & 1 & 4 \\
\hline Shoulder Pain & 7 & 3 & 4 & 4 & 6 & 24 \\
\hline Paraplegia/paresis & 2 & 3 & 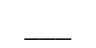 & 2 & - & 7 \\
\hline $\begin{array}{l}\text { Quadriplegia/ } \\
\text { paresis }\end{array}$ & 4 & 4 & - & 1 & - & 9 \\
\hline Incordination & 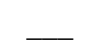 & 1 & _ & - & $\ldots$ & 1 \\
\hline Cerebral Palsy & 3 & 6 & 10 & 9 & 9 & 37 \\
\hline $\begin{array}{l}\text { Cervical } \\
\text { Spondylosis }\end{array}$ & 9 & 4 & - & - & - & 13 \\
\hline Knee Stiffness & 1 & 1 & - & 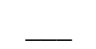 & $\ldots$ & 2 \\
\hline Erb's Palsy & 1 & 1 & - & 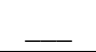 & _ & 2 \\
\hline TOTALI & 73 & 73 & 58 & 46 & 49 & 299 \\
\hline
\end{tabular}

\section{RESULTS}

Of the 195686 patients who attended the hospital between January 2002 and December 2006, 6473 (3.3\%) enjoyed physiotherapy services. Five thousand four hundred and seventy-one $(2.7 \%)$ were inpatients while $93.3 \%$ were outpatients. Seven hundred and sixty-six (14.0\%) inpatients received physiotherapy. Out of the 190, 215 outpatients, 180, 479 (94.88\%) were between 18 years and older. Majority (94.5\%) of the patients on outpatient physiotherapy were above 20 years of age. More female $(55.5 \%)$ participated in the stress management and health promotion (Table 2). More female (55.5\%) participated in the stress management and health promotion sessions (Table 2). Eight hundred and eight (15.3\%) of the physiotherapy patients/clients participated in stress management and health promotion.

The most common co-morbid health problems commonly referred for physiotherapy were low back pain, knee arthritis, stroke, cerebral palsy, shoulder injury and nerve injuries respectively (Table 3). The most common co-existing health problems referred for physiotherapy are low back pain $(85 ; 21.7 \%)$, knee osteo-arthritis $(82 ; 20.9 \%)$, stroke $(64 ; 16.3 \%)$ and shoulder pain (29; $7.4 \%$ ). Patients who did not present with physical disability or neuro-muscular problems were not referred for physiotherapy despite having mobility and postural problem that required physiotherapy. Majority $(82.5 \%)$ of the patients had inorganic psychosis including mild to moderate depression, anxiety, anger and eating disorders while $8.5 \%$ were referred due to complications from the treatment of organic psychotic illnesses.

\section{DISCUSSION}

Musculoskeletal injuries are not uncommon with mentally ill individual (Gbiri, 2007; 2011). These injuries occur indifferent ways including those sustained during restlessness/hyperactivities, substance abuse (for the injectables) or sometimes during restrain (Gbiri, 2007; 2011). Conditions like back pain, shoulder pain and injuries, arthritis, neuritis, sciatica, nerve injuries and musculo-skeletal injuries often affect 
intervention and recovery in individuals with mentally illness (Gbiri, 2007; 2011). Some mentally ill individuals are often bound to physically restrain the patient and forcefully brought into the hospital for therapy, especially the aggressive and violent ones. Some were restrained in either spiritual homes or traditional healing centres before orthodox medical intervention. The consequential neuro-muscular injuries are referred for physiotherapy (Gbiri, 2007; 2011). These injuries pose confusion to psychiatrist in the effective management of this group of patients because of choice of drug to avoid drug-drug interaction and complications. The involvement of physiotherapy in management of the neuro-muscular problems and pain go a long way in reducing drug-drug interactions.

Joint degenerative disorders and neuro-muscular injuries are the most commonly reported co-morbid conditions in the participants for this study. Some patients also present stroke with neurological problems and cognitive impairments. The experience of the authors shows that the inter-occurrence of these two neurological disorders pose lots problems for effective rehabilitation programme. These patients lack the ability to follow simple instruction during rehabilitation due to cognitive impairment secondary to either the stroke or the mental illness or both. Therefore, well-planned and meticulously monitored physical exercises with adequate knowledge and experience in neurology and mental illness could be an antidote to this problem. Physiotherapeutic modalities are also used to reduce pain and stress in an individual who abuses substances thereby improving habit resenting and modulate the brain rewarding system, thereby reducing dependency, and increase postdischarged abstinence rate and relapse (Gbiri, 2007; 2011). This is useful in developing where substance abuse is increasing (Rounsaville, 1986; Lurigio and Lewis, 1989; Lawal et al, 1999; Lawal et al, 2004; Ayorinde et al, 2004). It is however unfortunate that none of these drug and substance abuse patients have been referred for physiotherapy for any of these purposes. This is because that well designed therapy between the psychiatrists who has the primary responsibility to the patients' conditions and physiotherapists who will provide the adjunct therapy has not been well planned and tried.

\section{CONCLUSION AND RECOMMENDATIONS}

The importance of physiotherapy in mental health is evidenced in the number of patients/clients who benefited from its services. Therefore, physiotherapy is an integral and indispensible member of the mental health team. However, physiotherapy is still underutilized in the hospital. This points to the need for proper integration of physiotherapy into mental health team in the hospital and other similar health institutions.

\section{REFERENCES}

Ayorinde O, Gureje O, Lawal R 2004 Psychiatric research in Nigeria: Bridging tradition and modernisation. BJP. 184: 536-538.

Gbiri CA 2007. Stress, mental-health and quality of life. Presented at $7^{\text {th }}$ Health Round Table (HEART 7) organised by Emzor Pharmaceutical Limited.

Gbiri CA 2011. Physiotherapy in mental illness. A workshop organized by the Department of Physiotherapy, Faculty of Health Sciences, College Medicine, Nnamdi Azikwe University.

Gbiri CA, Badru, FA, Ladapo HTO and Gbiri AA 2011 Socio-Economic Correlates of Relapsed Admitted Patients in Nigeria mental health institution. International Journal of Psychiatry in Clinical Practice 15: 19-26.

Hare M. Physiotherapy in Psychiatry. Heinemann Physiotherapy, 23, Bedford Square, London WC1B 3HH; 1986.

Marlatt GA. Situation determinants of relapse and skill-training intervention. In Marlatt $G$, Gordon JR (eds). Relapse prevention. The Guild Press. New York. 71-127; 1985.

Nierman P, Lyons JS 2001 State mental health policy: shifting resources to the community: closing the Illiois State Hospital for Adolescents in Chicago. Psychiat Serv. 52:1157-1159.
Lawal RA, Adeyemi JD, Orija OB, Awofisayo AO 2004 Relapse precipitants in Nigerian drug abusers. Nig Postgr Med J. 11(1):15-20.

Lawal RA, Adelekan ML, Ohaeri JU, Orija OB 1999 A 12-month follow-up study of heroin and cocaine abusers managed in a Nigerian Psychiatric Hospital. EAMJ. 107-112.

Longabaugh R, Robnin A, Stout RL, Zywiak WH, Lowman C 1996 The reliability of Marlatt's Texonomy for classifying relapses. Addiction. 91:S73-S88.

Lurigio AJ, Lewis DA 1986 Worlds that fail: a longitudinal study of urban mental patients. J Soc Issues. 45:79-90.

Rounsaville BJ 1986 Clinical Implications of Relapse Research. In Tims FM and Leukefeld CG (eds). Relapse and recovery in drug abuse. Rockvlle, MD. US Department of Health and Human Services. 172-184.

Wise RA 1998 Drug activation of brain pathways. Drug Alc Depend. 51:13-22. 